\title{
Türk Kütüphaneciliğine Bir Amerikan Sisteminin Kazandırılması : Dewey Onlu Sınıflama
}

\author{
The Acquaintance of an American System to the Turkish \\ Librarianship : Dewey Decimal Classification
}

Sekine Karakaş

\begin{abstract}
Öz
Kütüphaneciliğimiz günümüzdeki olgunluk düzeyine erişene kadar önemli aşamalardan geçmiş, uluslararası etkileşim, mesleğin ilerlemesinde önemli bir rol oynamiştır. Gelişmiş ülkelerde kullanılan çeşitli yöntem ve tekniklerin sağlanması için yoğun bir çaba gösterilmiş ise de, bu ülkelerle paralel bir çizgiye gelinmesinde her zaman desteğe gereksinim duyulmuştur. Kütüphane hizmetinde en temel ögelerden biri olan Dewey Onlu Sinıflama Sistemi. Türkiye'deki kütüphanelerde oldukça gecikmeli olarak uygulamaya konulmuştur. Bu makalede, sistemin kütüphaneciliğimize kazandirılmasında, Amerikalı kütüphanecilerin destegi ve konuya verdikleri önem irdelenmiştir.
\end{abstract}

Anahtar sözcükler: Dewey Onlu sınıflama, Uluslararası etkileşim.

\begin{abstract}
Our librarianship has gone through very important phases until reaching todays maturity and international interaction played an important role during this time. Although an intensive effort was made for the adaptation and application of the methods and techniques used in developed countries, continued cooperation and upgrading for achieving desired level of excellence is still needed. As is known one of the basic services for users is a sound classification system which will enable them to reach the material they need easily. The introduction and application of the Dewey Decimal Classification System in Turkey was unfortunately delayed. Due to the encouraging support and importance extended to the problem by American librarians both in our country and abroad, this necessary service became available all over Turkey.
\end{abstract}

Keywords: Dewey Decimal classification, International interaction.

- Doç. Dr.: Ankara Üniversitesi DTCF Kütüphanecilik Bölümü ögretim üyesi. (akarakas@humanity.ankara.edu.tr). 


\section{Giriş}

Kütüphanecilik bilginin depolanması, erişimi ve elde edilmesi süreçlerinin her aşamasında çeşitli yöntem ve tekniklere gereksinim duyan bir bilim dalıdır. Geçerli bir tanıma göre kütüphanecilik, bu teknik ve yöntemierin toplumsal amaçlar çerçevesinde algılandığı, geliştirildiği ve uygulanmaya konulduğu bir çalışma alanı olarak görülür (Çakın, 1989, s.59). Kütüphaneciliğimiz gelişim sürecinde, özellikle kullanıcıya daha iyi hizmet verebilmeyi gerçekleştirecek teknik ve yöntemlerin sağlanmasında birçok ülkeden yararlanmış, ancak Türk kütüphaneciliğinde Amerikan etkisi ilk çağdaş adımlarda çok daha yoğun biçimde hissedilmiştir. Son 50-60 yll içinde gelişmiş ülkelerin, Türkiye gibi gelişmekte olan birçok ülkeye mesleki gelişme bağlamında yardımcı oldukları bilinmektedir. Çağdaş dünyada özellikle, iletişim alanında kaydedilen ilerlemeler sonucunda, kütüphaneler ayrı ayrı çalışmayı, farklı kurallar ve yöntemler uygulamayı bırakıp evrensel bir çizgide buluşmaya yönelmişlerdir. Türk kütüphane sisteminde süregelen düzenlemelerin en köklü biçimde değiştiği konuların başında, kitapların raflara alfabetik sırayla, renklerine, boylarına veya geliş sıralarına göre diziłmesi yerine, açık raflarda bir konu sınıflaması sistemine göre yerleştirilmesi gelir. Bu, kütüphanecilik alanında gerçekten bir boyut değiştirmedir. Türkiye gibi gelişmekte olan bir ülke kütüphaneciliği 50 yıl önce Amerikalı uzmanların desteği ile teknik bile sayılamayacak bir kütüphane düzeninden, araştırmacının doğrudan konusuna yönelebileceği bir erişim yöntemine geçmeye hazırlanmaktadır. Ancak yeni bir sistemin kabuiünde yalnızca dış etkinin geçerli olmadığını düşünen kişiler hep olagelmiştir. Örneğin, Adnan Ötüken, Dewey Onlu Sınıflama Sisteminin Türkiye'ye geliş nedenlerì olarak Milli Kütüphane ile Kütüphanecilik ve Bibliyografya Enstitülerinin kurulmalarını, kütüphanelerin sayı ve koleksiyon olarak artış içerisinde bulunduklarinı, açılan birçok çocuk kütüphanesini, genç ve bilgili bir kütüphaneci kuşağının gelişmekte olmasını, meslek dergilerinin yayınlanmaya başlamasını göstermektedir. Ona göre bu iç etkenlere Amerika Birleşik Devletleri'nin maddi ve manevi destekleri eklenince Dewey Onlu Sınıflaması Türkiye'de de uygulanmaya başlamıştır (Pakin, 1972, s.153).

Bu çalışmada, daha önceki makalelerin bir devamı olarak (Bakınız, Karakaş 1997, 1999) Ankara Amerikan Kütüphanesi'nin arşivinde bulunan ya- 
rım asırlık orijinal mektup ve belgelerden hareketle Türk kütüphaneciliğinde Amerikan etkisi irdelenmeye ve Dewey Onlu Sınıflama Sisteminin Türkiye'de uygulanmasının, her iki ülke kütüphanecilerinin yoğun çabaları sonucunda nasıl gerçekleştiriłdiği gösterilmeye çalışılmıştır.

\section{Uluslararası Etkileşim}

Ülke kültürlerinin birbirlerini etkilemeleri bağlamında öncelikle teknik gelişmelerin yer aldığı bilinmektedir. Özellikle gelişmekte olan ülkeler, ekonomik büyüme ve çağdaşlaşma sürecine girdikten sonra, biraz da zorunlu olarak uluslararası yardımlaşma noktasına gelmekte, belirledikleri hedeflere erişebilmek için yabancılardan düzenli biçimde destek almaktadırlar. Gelişmiş ülkeleri kendilerine model alan ve gelişmeye yönelik kuramsal rehberlikten yararłanan ülkeler, bu diş destek ve teknik yardımla fikir, bilgi ve teknoloji transferi yapmaktadır. Gelişmekte olan bir ülke olarak Türkiye'de, kütüphanecilik alanında da doğru seçimıeri yapmak ve öncelikieri belirlemek her zaman güç olmuştur. Ancak dünyadaki gelişmelere ayak uydurma zorunluluğu nedeniyle de, geleneksel yöntemlerden vazgeçmenin ağırlığına katlanarak yeniliklerin benimsenmesi ve uygulanması yönünde uğraşı vermek yine mesleğini geliştirmek için çalışan kütüphanecilere düşmüştür. Gelişmeye ve yeniliğe açık kütüphaneciler, ussal mevsim değişiklikierinin çeşitli nedenlerle yavaş geliştiğinin, bu yeniliklerin önce belirli bir grup ya da gruplar tarafından benimsendiğinin ve daha sonra diğer uygulama alanlarına yayılabileceğinin bilincindedirler (Benge, 1970, s.15). Gassol de Horowitz, Jesse H. Shera'nın 1965 'te yazdığı "Libraries and the Organization of Knowledge" adlı eserinde, bir toplumsal araç olarak kütüphanelerin, içinde bulundukları toplumun tarzına ve amaçiarına uygun biçimler aldığını söylediğinden bahsetmektedir (Gassol de Horowitz, 1988, s.3). Bu olgu Türkiye için de geçerli sayılabilir. Ülkemizde Cumhuriyet' in ilanından bu yana, kütüphaneciliğimiz de diğer pek çok dalda olduğu gibi ağır bir tempoda ilerlemiştir. Türk kütüphanecilerinin her vesile ile kütüphanelerimizde kataloglama, sınıflama sorunlarının çözülemediğinden yakınmakta olduklarına bakılırsa (Ersoy, 1983, s.52), kütüphane hizmetinde en temel öğelerden biri sayılan sınıflama sisteminin ülkemizde uygulamaya konulmasındaki gecikme öyküsü daha da ilginç görünmektedir. 
Melvił Dewey, 1872 yılında Harris'in sınıflama sırasından yola çıkarak, konuya göre yerleştirilmiş kitaplara onlu olarak kullanılan Arap rakamlarının uygulanışından ibaret bir sistemi tasarladığı zaman henüz 20 yaşında bir kolej ögrencisi idi. Bu on rakamının sihirli gücü, insanın düşünce yaşamını sınıflamada kullanarak kütüphanecilerin en zor işi olan yayın konulandırmasına da bir açıklık getirmek suretiyle kolayłaşmasını sağlamıştır (Pakin, 1974, s.227). Bu tasarımın ilerletilmesi, genişletilmesi, Amherst Koleji Kütüphanesi'nin düzenlenmesinde kullanıımasının ardından, "Bir Kütüphanenin Kitap ve BroşürIerini Fişlemek ve Tanzim Etmek İçin Bir Sınıflama ve Endeks" adlı eserin yayınlanması (1876) arasında yalnızca dört yıl geçmişti. Yaklaşık bir asır sonra sistemin yalnızca çevirisinin Türkçe'ye kazandırılması için çok daha uzun bir süre geçecekti. Gerçekte 50 yll önce kütüphaneler gibi kurumlarla henüz güçlü bağların kurulamadığı bir ülkede gelişme, değişme hamlelerinin hemen yapılması çok da kolay değildir. Ancak, özellikle her zaman kıt kaynaklarla kullanıcı hizmetini iyileştirme çabası içindeki kütüphaneçiler için, daha iyi işleyen, hedefe daha kolay varmayı kolaylaştıran yöntemlerin bulunması son derece önemlidir. Çağdaş gelişmelere her zaman set vuran bürokratik engeller, zaten kütüphaneler gibi kurumlarla henüz güçlü bağların kurulamadığı Türkiye'de, işlerin daha da yavaş yürümesine neden olmuştur. Yine de gerekli yöntem ve yaklaşımların Amerika'dan alınması gündeme geldiğinde Türkiye'de yeniliğe, gelişmeye açık, kütüphaneciliği meslek edinmiş, Türklerle ilişkide bulunan Amerikałł yetkililer, üst düzey bürokratlar ve devlet erkanı iłe temaslarını sürdürerek, sistemin ülkeye kazandırılma sürecini başılatmaya kararlı bir tutum göstermişler, bu çabaları da meyvasını vermeye başlamıştır.

\section{Ilk Temaslar}

15 Aralık 1951 tarihinde dönemin Milli Eğitim Bakanı Vekilinin imzası ile Amerikan Haberler Bürosundan Latimer'e gönderilen mektupta ફ̧unlar yazıyordu:

"Kıymetli yardım ve tavassutunuzla Amerika Birleşik Devletleri Hükümet: tarafından memleketimiz kütüphanelerinde tetkikler yapmak üzere gönderilmiş bulunan Prof. Dr. Thompson, Milli Kütüphane Müdürü Adnan Ötüken’le yaptığı görüşmeler sırasında Milli Kütüphanemizin ve diğer Türk kütüphanelerinin sistematik katalog çalışmalarında faydalanımak üzere aşağıda adları 
zikredilmiş olan tasnif şemalarının en yeni şekilleriyle dilimize çevrilmesinin faydalı olacağını ve bu tercüme işinde Amerikan Haberler Bürosunun bize yardıma amade bulunduğunu bildirmiştir. Bu iki eserin Türkçeye çevrilmesiyle kütüphanelerimiz değerli vasıtalar elde etmiş olacaklardır. Eserlerin Türkçeye çevrilmesi sırasında Milli Kütüphane mensupları da tercüme işini kendisine havale edeceğiniz zata yardıma hazırdırłar. Vücuda getirilecek tercümenin ilerde bastırılması mümkün olursa, şüphesiz ki bu hizmetin şumulü (kapsamı) genişletilir."

Mr. Latimer'in bu husustaki yardımlarını isteyen Bakan Vekili, mektuba Melvil Dewey tarafından yazılan Decimal Classification ve Minnie Earl tarafından yazılan List of Subject Headings adlı eserlerin kimliklerini de eklemiştir.

Amerikan çizgisinde bir Türk kütüphane sistemi kurulmasına yönelik çaıışmalar yapan Emily Dean, kütüphanecilik eğitimi için son derece gerekli gördüğü Dewey Onlu Sınıflama Sisteminin Türkçeye çevirisi konusunda da temaslarını sürdürmektedir. Emily Dean, Milli Eğitim Bakanına hitaben kaleme aldığı 29 Temmuz 1953 tarihli yazıda Dewey Decimal Classification adlı kitabın Ankara Üniversitesi doçentlerinden B. Nusret Hızır'a verildiğini söyler ve bunların bilirkişi tarafından kontrol edilmesini ister. Bilirkişilik görevi Ferit Soner ve Vedat Örs'e verilir.

Türkiye'ye gelen ilk Amerikalı kütüphanecilerden biri olan ve hazırladığı raporla Türk kütüphanecilik tarihine geçen Lawrence $S$. Thompson, Amerika'ya döndükten sonra Kentucky Üniversitesi Kütüphaneleri Müdürlüğüne getirilmiştir. Thompson 23 Mart 1953'de Kongre Kütüphanesi görevlilerinden Verner W. Clapp'a yazdığı mektupta Dewey Onlu Sınıflama Sisteminin Türkçeye çevirisine ilişkin çok ilginç noktalara değinmekte ve şöyle demektedir: "Size bu konuda hangi bilgilerin ulaştığını bilmiyorum ancak Ankara'dan bir yıl önce ayrıłığım zaman Dewey'in çevirisine uygun düzenlemelerin yapılacağına ilişkin bir kanı vardı. Bu düzenlemelere özellikle din, (belki de bu bölümü tamamen gözden geçirmek gerekecekti), Osmanlı İmparatorluğu Tarihi, Yakın Doğu ve Modern Türkiye, yasal sistemler (artık Türkiye'de şeriat'ın pek önemi kalmadığından İspanya uyarlaması burada kullanılabilir) alanlarında intiyaç duyulacaktır. Emily Dean o zaman bu işi yürütebilecek nitelikte 
pek çok kimse olabileceğini düşünüyordu. Türkiye'den döndüğümden bu yana İkbal Argon Amerikan Kütüphanesỉndeki görevine döndü. Sistemin uyarlamalarının onun dikkatli eleştirileri ile doğru yönlendirileceğine içtenlikle inanıyorum. Kanımca tek başına hiç bir proje, iyi yürütüldüğü takdirde, Türk kütüphanecilerin Amerikan kütüphaneciliğinin kendileri için en yararlı ve en verimli yönlerini almalarına bunun kadar yardımcı olamaz. Türkiye'deki kütüphaneciler, bugün birkaç kütüphaneci arasında daktilo veya elle çoğaltılmış olarak dolaşan ve iyi uyarlanamamasına neden olarak zayıf mazeretler gösterilen UDC'nin eski basımından başka bir sınıflama sisteminden yoksun olduklarından bocalama içindeler."

Dr. Thompson'un mektubunda belirtildiği gibi Emily Dean, Sinıflamanın Türkçe'ye kazandırılma sürecini hızlandırmak için Türkiye'de yeniliğe yatkın kişilerle gerekli altyapıyı oluşturmaya çalışıyor, konu ile ilgili bilgileri de Amerika'daki yetkililere aktarıyordu.

Emily Dean 1954'de Dil ve Tarih-Coğrafya Fakültesi Kütüphanesine, sekiz yıl Süleymaniye Kütüphanesi Müdürlüğü yapmış olan Dr. Mustafa Köymen'in atanmasından duyduğu memnuniyeti Arnold'a bildirmiş, yeni yöntemlere meraklı olan Köymen'in kimsenin erişemediği kitapları Dewey'e göre sınıflamak istediğini yazmıştır (Karakaş, 1999, s.392). Emily Dean ayrıca 31 Mayıs 1954'de Ford Vakfı Başkan Vekili Edwin G. Arnold'a yazdığı mektupta, Columbia Kütüphanecilik Dekanı ve Türkiye'de kütüphanecilik alanındaki gelişmelerle yakından ilgilenen kişilere, bu gelişmelerin çok önemli bir göstergesi olarak Dewey Onlu Sınıflamanın 15'inci gözden geçirilmiş basımının Türkçe'ye çevrilmekte olduğunu (Amerikan Haberler Merkezinin desteği ile) anlatmaktadır. O yaz mevsiminde Milli Eğitim Bakanlığı tarafından yayınıanması planlanan eserin, kütüphanecilik eğitimi için Türkiye'ye gelecek yabancı öğretim elemanlarına büyük ölçüde yardımcı olacağını söylemektedir.

\section{İkbal Argon'un Koordinatörlüğü}

Çeviri projesinin yürütücülerinden biri Amerikan Kütüphanesi personeli olan İkbal Argon'du. Emily Dean, 6 Mayıs 1957'de Amerikan Idare Heyeti Neşriyat Dairesinden Robert Avery'e yazdığı mektupta, Sınıflamanın koordinatörü 
olan Ikbal Argon'un "Din" ile ilgili olarak 230 ve 260-280 numaralı bölümlerinin gözden geçirilmesi gerektiğini düşündüğünü yazmakta ise de çalışmayı bütünüyle denetlemeye gönderdi. Çevirinin doğru ołmasını dileyen Emily Dean, özellikle Hıristiyan dinine yönelik terminoloji yanlışlarından çekinmekle, böyle durumlarda Amerika'da yapılacak değişikliklerin Türkçe kopyasına yazılmasını talep etmektedir. Türkçe metnin ikinci bir kopyası olmadığından yakınan Emily Dean aynı yılın sonbaharında tüm sınıflamanın basıımış olabileceğini söylemektedir.

5 Haziran 1957'de İkbal Argon ve Amerikan Hükümeti arasında bir anlaşma imzalandı. Buna göre Dewey Onlu Sınıflamasının 15. basımı 31 Aralık 1958'e kadar tamamlanacaktı. Yarım yüzyıl önce Türk kütüphaneciliğine bugün de kullanmakta olduğumuz bu yöntemin kazandırılmasında önemli bir rol oynayan Ikbal Argon, Amerika Birleşik Devletleri'nde o yıllarda halk kütüphanelerinin yaklaşık hepsinde ve diğer kütüphanelerde de büyük öłçüde benimsenen Dewey Onlu Sınıflamasının Latin Amerika, Avrupa, Asya, Afrika ve Avusturalya'da da kullanılmakta olduğunu, kısmen Çince, Japonca, Fransızca, Almanca, İtalyanca, İspanyolca, Portekizce, Norveçce, Macarca, Çekce ve son defa da Türkçeye tercüme edildiğini söylemektedir (Argon, 1961, s.26).

\section{Basım Hazırlıkları}

USIS (Amerikan Haberler Merkezi), Milli Eğitim Bakanlığı ile 14 Mayıs 1952 'de yaptığı anlaşma uyarınca Dewey Onlu Sınıflamanın 1500 kopyasının yayınlanabilmesi için gerekli kağıt alımı masraflarını karşılamak üzere $5.460 \mathrm{TL}$. verdi. Bu para hemen değerlendirilmiş, satın alınan kağıtlar, diğer USIS çevirileri için alınan kağıtlarla birlikte Bakanlığın deposuna konulmuştur (7 numaralı mektup).

Milli Eğitim Bakanlığı, Dewey Onlu Sınıflamayı kendi matbaasında basmayı üstlenmiştir. Ancak bu işle yakından ilgilenen Milli Kütüphane Müdürü Adnan Ötüken'in işinden ayrılarak yurt dışında eğitim ataşesi olarak görev yapacağını duyan Amerikałılar projenin geleceğinden endişe duymaktadır. Ayrıca Ötüken, Milli Eğitim Bakanlığı Matbaasının iş yükünün çok fazla olduğundan kitabı belki de bir yılda basamayacaklarını söylemiştir. Ankara'daki 
matbaanın da çok iyi olmayışı, Sınıflama gibi karmaşık bir kitabın İstanbul'da basılmasını gerektirmektedir. Bu ise Sınıflamanın müsveddelerinin kontrolünün ve düzeltmelerinin Ankara'dan yapılmasını güçleştirmektedir. Milli Eğitim Bakanlığı basıma geçmeden elle yazılmış metnin tümünü istemekte, israr edilecek olursa Sınıflamanın henüz birinci yarısı basıma hazır olduğundan, daha fazla gecikmeye neden olacağını hissettirmektedir.

Adnan Ötüken, Sınıflamanın İstanbul'daki matbaadan çok daha üstün olanaklara sahip Ankara'daki Türk Tarih Kurumunda basılmasının daha iyi olacağını düşünmektedir. Sınıflamanın basımında çok değişik boy ve biçimlerde baskı kalıpları gerekeceği için matbaanın da mükemmel olması önem kazanmaktadır. Ayrıca Tarih Kurumu Basımevi kitabı çok daha kısa zamanda basacak ve baskıya başlamadan önce elle yazılmış metnin tamamı da gerekmeyecektir. Adnan Ötüken bu işi Tarih Kurumuna para ödenmeden yaptırabileceğini de söylemektedir.

Emily Dean, Sınıflamanın basımı ile ilgili olarak karşı karşıya kaldığı ikilemi Amerika'daki yetkililere 1957 yılında yazdığı mektupta şöyle aktarır: "Sınıflama en iyi Tarih Kurumunda basılacağına göre seçilecek iki yoldan biri, satın alınan kağıtları Milli Eğitim Bakanlığından alarak baskı ve ciltleme karşılığı olarak Kuruma vermek olabilir. Diğer bir yol, USIS'in çeviri programı fonundan Tarih Kurumuna gereken ödemeleri yapması ve elde kalan kağıtları da diğer çeviri projeleri için kullanmasıdır."

Emily Dean, Kerwin ve Adamson'a yazdığı mektubu şu cümlelerle bitirir. "Bu Sınıflamanın önemini ve bunun Türkiye'deki kütüphanelerin gelişmesine ne büyük ve kalıcı bir katkısı olacağını kavradığınızdan eminim."

12 Haziran 1957'de Dewey Onlu Sınıflamanın çevirisi tamamlanma yoluna girmiştir, 16. basımın dil, edebiyat, Avrupa ve Asya tarihi ile ilgili bölürnlerinin son anda çeviriye dahil edilebilmesi eserin değerini artırmıştır. Ancak bu doğal olarak yapılanłarın tekrar kontrolünü ve tekrar daktilo edilmesini gerektirmiştir.

Avrupa ve Asya tarihinin Türkiye için özellikle önemli olduğunu düşünen Amerikalı kütüphaneciler, 15. basımın oldukça yetersiz olduğu 940 ve 950 bölümlerinin çeviriye girmesine özellikle memnun oldular. 
İkbal Argon Ankara Üniversitesinin önde gelen tarihçilerinden Prof. Şinasi Altındağ ile iki görüşme yaptı. Prof. Altındağ daha önce Sınıflamanın tarihle ilgili bölümünü çevirmiş olduğundan yeni şemanın eski çalışmaya dahil edilmesi konusunda en iyi kararı verecek olan şahıstır. Bu çalışmada, Avrupa Tarihinin çok ayrıntıł bölümleri dışta bırakıımış ise de, Asya ile ilgili tüm yenilikler dahil edilmiş ve Sınıflamanın kullanışılığını artırmıştır.

Sınıflamanın bütünü her alanın uzmanları tarafından tercüme edildi. Seçilen sözcüklerin Milli Eğitim Bakanlığının uygun gördüğü biçimde kullanılıp kullanılmadığını kontrol etmek için, biri Amerika'da okumuş bir kütüphaneci, diğeri de Siyasal Bilimler Fakültesinde Ingilizce hocası olan iki denetleyici seçildi. Uzmanların terminoloji konusunda karşılaştıkları sorunlarının çözülmesinde yine İkbal Argon yardımeı oluyordu.

Sınıflama tamamlandığı zaman Milli Eğitim Bakanlığı bu işi basmayı üstlenmiş ise de, işlerinin yoğun olması nedeniyle ancak bir yıl sonra basabileceklerini söyleyince, Amerikalı uzmanlar önce düş kırıklığına uğramış ancak daha sonra bunun bir avantaj olduğunu düşünmüşlerdir. Sınıflamanın çevirisi Ankara Üniversitesi Kütüphanecilik Okulu'nun ders programına alındığına ve Milli Kütüphanede hazırladığı sınıflanmış katalog için bu çalışmaya ivedilikle intiyaç duyduğuna göre, bu üç ilgili taraf işi ve harcamayı bölüşerek SInıflamayı teksir edebilirlerdi. Kütüphanecilik Okulu, Amerikan Kütüphane Derneği kanalı ile mumlu kağıtları aldı ve gönderdi, Amerikan Haberler Merkezi mumlu kağıtların daktilo giderlerini karşıladı, Milli Kütüphane basılacak kağıtları aldı ve teksir işini üstlendi. Bütün bu işlerin 1957 yılının Haziran ayına kadar bitmesi planlanıyordu.

Sınıflamadan 150 kopya teksir edilerek Kütüphanecilik Bölümü öğretim elemanlarına, öğrencilerine, Milli Kütüphane çalışanlarına ve Sınıflamaya başlayan diğer kütüphanelere dağıtılacaktı.

Daha sonraki iki yıl zarfında Kütüphanecilik Okulu Müdürlüğü yapan Prof. Elmer Grieder "Sınıflama" ile ilgili yararlı öneriler getirmiş, onun yerine gelen Prof. Lewis Stieg, Sinıflama ile çok daha yakından ilgilenmeye başlamıştır. $O$ da bu sistemin, Türkiye'ye kazandırılması için bütün çaba gösterenler gibi, Sınıflamanın basımdan önce teksir edilmesinin yararına inanmakta, hataların 
ve açıklamaların yetersiz olduğu kısımlar kolaylıkla görülebileceği için, iyileştirmelerin daha iyi yapılacağını, Türkleri ilgilendiren konularda eklemelerin daha kolay test edilebileceği düşünmektedir. Dr. Stieg, Ikbal Argon'la ve tarihçi Prof. Altındağ ile çok yoğun çalışmaya başlamış, ayrıca Sınıflama şemasındaki Türk Tarihi, Türk Dili ve Edebiyatı ve İslam Dini bölümleri için de uzmanlarla yakın ilişki içine girmiştir.

Słnıflama son biçimini alınca İkbal Argon, basımından sonra eklenecek dizini yapmaya başlamasına rağmen teksir edilmiş Sınıflamada dizin yer alamamıştır.

\section{Basım}

Dewey Onlu Sınıflama Sisteminin 15. basımının çevirisi sürerken Amerika'da 16. basımın hazırlıkları devam etmektedir.

16. basım için hazırlanan şemaya bakıldığında, 14, basımda yer alan Dünya Savaşından önce, Osmanlı İmparatorluğu dönemindeki dünya haritasının aynen bu yeni şemada da yer aldığının görülmesi oldukça şaşkınlık yaratmıştır. Yerleşmiş numaraların değişmesinin güçlügü anlaşılınca, bu numaraların Türkiye için genişletilmesinin, herhangi bir değiştirme yapılmasına gerek duyulmadan, önemli bir iyileştirme sağlayabileceği düşünüldü.

15. basım, Türkiye'nin önemli kentlerinden bazılarını kapsamıyordu, ayrıca kentlerin eski yazılışı da artık kullanılmıyordu. Örneğin Smyrna yerine İzmir deniyordu. Kıbrıs artık Türkiye'nin bir parçası olmadığı için 956.4 de yer alması gerekmiyor, Konya ve Adana gibi Türk şehirlerinin de 956.45 de buIunması çok mantıklı gelmiyordu. Ermenistan bir politik varlık olmaktan çıktığından, bu numara yalnızca önceki zaman|ara ilışkin çalışmalar için kullanılabilirdi.

Prof. Altındağ, Amerikalıların talebi üzerine modern Türkiye için aşağıda verilen listeyi hazırladı. Bu łiste yeni bir basıma konulmak için oldukça uzun olmasına karşın, aynı genel düzenleme korunursa yeni sınıflama eskisinin üstüne olgulara çok daha iyi uyum sağlayacaktı. Ancak her durumda kent adlarının modernize edilmesi gerekliliği Kongre Kütüphanesi, Dewey Onlu Sınıflama Sistemi Editörlük Bürosuna bildirildi. 
Dewey Onlu Sınıflamanın 16. basımında, Türkiye için önerilen sınıflama ફ̧eması şu şekilde yer almakta idi:

956.1 Türkiye, 1918.

1923'de Türkiye Cumhuriyeti Asya'yı, İstanbul'u ve Doğu Trakya'yı içeriyor. (Osmanlı İmparatorluğu 946.61'de sınıflanmalıdır).

- 02 Atatürk dönemi (1918-1938) (Atatürk 1880-1938)

- 021 Bağımsızıık Savaşı (1919-1923)

- 022 Devrimler (1922-1938)

- 023 Dış Politika (1922-1938)

- 03 Ikinci Dünya Savaşı sırasında Türkiye (1939-1945)

- 04 İkinci Dünya Savaşı'ndan sonra Türkiye (1945-

- 2 Avrupa'daki Türkiye, İstanbul, İstanbul Boğazı, Çanakkale Boğazı, Edirne

- Türkiye'deki Asya (Anadolu)

- 31 Batı Türkiye (Ege Bölgesi) İzmir, Bursa, Afyon

- 32 Karadeniz Bölgesi, Trabzon, Samsun, Amasya

- 33 İç Anadolu, Ankara, Konya, Eskişehir, Sivas

- 34 Güney Türkiye (Fırat'nn Doğusu) Diyarbakır, Urfa, Van, Erzurum, Kars.

\section{Sonug}

Üzerinde bulunduğumuz dünya, kuruluşundan günümüze kadar en güçlü uluslararası etkileşimi 20. yüzyılda yaşadı. Özellikle, İkinci Dünya Savaşından sonra yoğunlaşan teknolojik ve kültürel geçişlilik, hem teknoloji, hem de kültürel göstergeler kütüphanecilik ve enformasyon bilimlerinde kendisini gösterdi. Gelişmekte olan ülkeler, sınırların dışında kalan hamleleri izlemek ve uygulamaya koymak üzere çeşitli yollardan geçtiler. UNESCO gibi kuruIuşlar ile Amerika Birleşik Devletleri, Almanya, Fransa gibi Avrupa ülkeleri kü- 
tüphanecilik alanında yeniliklerin, kavramların ve fikirlerin, gelişmekte olan ülkelere aktarılması için çaba gösterdiler.

Daha önceki çalışmalarımızdan edinilen izlenimlerle bỉrlikte, bugüne kadar incelenen mektupların ve belgelerin ışığında, Amerika Birleşik Devletleri'nin bizim kütüphaneciliğimiz üzerinde böylesine etkili oluşunun en önemli nedenlerinden birinin, o ülkenin bunu bir politika olarak benimsemesi olduğunu söylemek mümkündür. Birleşik Devletlerin kütüphane bilgisinin ülke dışındaki rolünün, Amerikan dış politikasının kullandığı ögelerden biri olduğu düşünülebilir. Leon Carnovsky'nin 1950'li yıllarda derlediği "International Aspects of Librarianship" adlı eserin önsözünde, Amerikalı kütüphanecilerin yurt dışındaki meslektaşlarına Amerikan kütüphane uygulamalarının, ne denli iyi olduğunu göstermek için neler yaptıklarını, örgütlü olarak gelecekte hangi politikaları izleyeceklerini sormaktadır (Carnovsky, 1954). Amerikalı uzmanlar gerçekten de Türkiye'deki kütüphanecilik sistemine doğru teşhislerle yaklaştılar. Amerikalı kütüphaneciler tarafından tüm gelişmekte olan ülkelerde olduğu gibi Türkiye'de de en önemli eksikliğin yöntem geliştirme olduğunun anlaşıtması üzerine, onlar da bu konu üzerinde önemle durmaya başladılar.

Türkiye'de, kütüphanecilik mesleğinin gelişmesinde Amerikan kütüphaneciliğinin etkilerinì inceleyen çalışmalarımızın sayısı arttıkça bu etkinin de daha fazla şekillendiği söylenebilir. Ancak Türkiye, tarihsel geçmişi boyunca örneğin matbaanın girişinde olduğu gibi yenilikleri kazanmada, benimsemede ve uyarlamada, oldukça ağır gitmekte, hatta geç kalmaktadır.

Melvil Dewey, 1887'de Columbia Kolejinde kütüphaneci iken, bugüne göre basit sayılabilecek ilk kütüphanecilik okulunu açtı. Bu okulu diğerleri izlediyse de, hepsinde ders programı oldukça basitti: kataloglama, sınıflama (özeliikle bu şekilde etkin bir propagandası yapılan Dewey Onlu Sınıflama Sistemine dayanılarak), dĭger rutin işlemler, uygulamalar ve Dewey’in yeniliklerinden biri olan elyazısının kullanımı (Munthe, 1964, s.130). Ondokuzuncu yüzyılda Amerikan kütüphanecilik okulları programlarında ilk sırayı oluşturan sınıflama dersleri, Türkiye'de 1956-1957 tarihli Kütüphanecilik Enstitüsü Kütüphanecilik Dersleri Müfredat Programında yer almıyordu. 


\section{Kaynakça}

Argon, I. (1961). Dewey Onlu Tasnifi. Carl. M. White (ed.) Amerikan kütüphanecilik tecrübeleri, kütüphanelerin mazisi, tipleri ve kütüphanecilikte bugünkü davranış, içinde (s. 25-29). Ankara: Güven Matbaası.

Benge, R. C. (1970). Libraries and cultural change. London: Clive Bingley.

Çakın, İ. (1989). Kütüphanecilik : Bilim dalı olarak tanımı ve özellikleri. Türk Kütüphaneciliği, 3(2): 59-64.

Ersoy, O. (1983). Kütüphaneciliğimizi etkileyen nedenler. Türk KütüphaneciJer Derneği Bülteni, 32(2): 49-53.

Gassol de H. R. (1988). Librarianship: A Third World perspective. NewYork: Greenwood Press.

Carnovsky, L. (Ed). (1954). International aspects of librarianship. Chicago: The University of Chicago Press.

Karakaş, S. (1999). Türkiye'de ilk kütüphanecilik bölümünün kuruluşu ve Emily Dean. Türk Kütüphaneciliği, 13 (4): 376-396.

Karakaş, S. (1997). Türk kütüphaneciliḡinde Anglo Amerikan etkisi. Türk Kütüphaneciligi, 11(1): 8-19.

Munthe, W. (1964). American librarianship from a European angle. Hamden, Connecticut: The Shoe String Press.

Pakin, E. (1974). Dewey Tasnif Sistemi ile Evrensel Onlu Sınıflama'nın uygulama alanları. Türk Kütüphaneciler Derneği Bülteni, 23 (4) : 227-232.

Pakin, E. (1972). Dewey Tasnif Sistemi'nin Türkiye'deki uygulaması. Türk Kütüphaneciler Derneği Bülteni, 21(3): 150-158. 
Mektuplar: (Metindeki Siraya Göre)

1. Milli Eğitim Bakan Vekilinden Mr, Latimer'e (15 Aralık 1951).

2. Emily Dean'den Milli Eğitim Bakanı'na (29 Temmuz 1953).

3. Lawrence S. Thompson'dan, Mr.Verner W. Clapp'a (23 Mart 1953).

4. Emily Dean'den Mr. Edwin G. Arnold'a (18 Haziran 1954).

5. Emily Dean'den Mr. Edwin G. Arnold'a ( 31 Mayıs 1954).

6. Emily Dean'den Mr. Robert Avery'e (6 Mayıs 1957).

7. Emily Dean'den Mr. Kerwin ve Mr. Adamson'a (14 Mayıs 1957). 


\section{Mektup 3: Lawrence S. Thompson'dan, Mr. Verner W. Clapp'a University of Kentuck \\ The Library}

Mr. Verner W. Clapp

Chief Assistant Librarian

The Library of Congress

Washington 25, D. C.

\section{Dear Verner:}

I don't know just what communications reached you about the Turkish translation of the Decimal Classification, but it was the understanding of everyone in Ankara when I left there a year ago that appropriate adaptations would be made when the D.C. was translated. Such adaptations would be needed particularly in the field of religion (probably necessary to revise this completely), history of the Ottoman Empire, the Near East, and Modern Turkey, legal systems (probably the Spanish adaptation would be useful here, since the Shariat is no longer of any importance in Turkey). Mrs. Dean had in mind at that time several very able people who would be competent to handle this work.

Since I left Turkey, Mrs. Ikbal (Berk) Argon, whom yof know, has gone back to work in the American Library. I would expect that many of the adaptations would be subjected to the critical scrutiny of Mrs. Argon, and I would trust her implicitly.

I believe that no single project, if properly executed, would be of more importance in orienting Turkish librarians to those aspects of American librarianship which will be useful and fruitful for them. At present they are floundering, with no classification available to them except an old edition of the U.D.C. with some poor excuses for adaptation which have been typed and circulated in manuscript among a few Turkish librarians.

Sincerely,

Lawrence S. Thompson

Director of Libraries

LST: jas

cc-Mrs. Emily Dean : I did'nt realize this was still hanging fire, but I hope this note will do some good. .. Beria, Melahat, and Ilhan seem to be doing very well, and we are pleased with all of them. 


\title{
Mektup 5: E. Dean'den, E.G. Arnold'a
}

\section{University of Kentucky}

The Library

\author{
Mr. Edvin G.Arnold Deputy Director \\ Division of Overseas Activities \\ The Ford Foundation \\ 655 Madision Avenue \\ New York 21, N.Y.
}

May 31,1954

\section{Dear Mr. Arnold}

We were so glad to get your letter of May 19th saying that there would be no difficulty in arranging for a translater for the proposed Ankara Library School. We have found from Dean Kurat that he mailed the Foundation's letter back to you a few days after I wrote to you should have it by now.

We are delighted that you have begun the search for the library school teacher to come out here. Your suqqestion about having the Columbia or Chicago Library School sponsor the project seems a good one. My only fear is that it might slow down the process of getting the school open if they were put in charge of the operation. Of course it would be extremely valuable to have their advice on every step, and if they would select the teacher it would be fine, and it would certainly be advantageous to have him take all his direction from the Library School, as to buying books and other equipment, and the planning of courses. But I have a feeling that once he is selected, things will move faster if he can take the initiative, on advice from a Library school, but directly responsible to the Foundation. However, I may be all wrong, and perhaps the Library School will be so interested that they will push the project along rapidly.

If the teacher can be found this summer and get out here in time to organize one or two introductory courses for the first semester which opens Nov. 1st, a year's time will be saved. Under Turkish university rules, students must select their field of study in their first year, and take some courses in it each year. In the case of Library Science, the bulk of the work will be concantrat- 
ed in the last two years, but some courses in it must be taken the first two years. We are hoping that the University will let some 2nd year students switch to the Library field, so that we can get some graduates in three years. Therefore if the teacher can get out here to open the school this year it will be a great advantage. If he cannot get here by Nov. 1st perhaps he can for the 2nd semester, beginning Mar. 1st, which might serve the same purpose of getting the school started in 1954-55.

We are so glad to hear that you have been in touch with $\mathrm{Dr}$. Thompson as he knows all the problems. About his suggestion for the translator, Ikbal Argon does not want the job as she does not like to translate and prefers to stay in her present position. Melahat Ahiskali would be excellent, but if the teacher could get out here by October, she woold not be available. However, there are other suitable people here who have had some library experience, so I do not think we will have any difficulty in finding a good translator.

It is very kind of $\mathrm{Dr}$. Thompson to offer to select the professional literature but I think it should be selected by the teacher in consulation with the advising Library School.

We are constantly in touch with Adnan Otuken who is a member of the faculty committee which approved of the Library School project. It was he who suggested the name of Prof. Downes, head of the University of Illinois Library School, as a candidate for teacher.

Dr. Thompson's outline of the qualifications for the teacher is perfect and we hope it can be achieved. Dr. Thompson himself has all the qualifications, and I had favored the idea of his coming out, but when I mentioned the possibility to Adnan Otuken, after he returned from his trip to America, he said "No" that Dr. Thompson did not have experience in library school teaching and administration, which is true, and as Adnan Otuken feels that way and he will be influential in the attitude taken toward the school, I think it would be better to get another person. Also Dr. Thompson said about a year ago that he would not want to live overseas for so long. But of course, he may have changed his mind. I think if no better candidate is available that he could do the job well, but a great effort should be made to get someone with all the qualifications. 
It is very fine that Dean White of the Columbia Library School (incidentially my school) is interested. Being in New York, if they would undertake active participation in the project, it would be perfect. You might mention to him and the others that the Dewey Decimal classification, 15th revised edition, has been translated into Turkish (sponsored by the U.S. Information Service) and will be published this summer by the Ministry of Education. This will be of great help to the library teacher.

As this project is my favorite interest I will be very glad at any time to give any information that I can. If a candidate were considering the position and wanted to know specific details about the educational set-up or living condition. I would be very happy to write him.

We are sending a copy of this letter to Mr. Culbertson in Beirut.

Sincerely yours,

Mrs. Emily M. Dean

Director,

U.S. Information Library 


\section{Mektup 6: E. Dean'den, R.Avery'e}

Mr. Robert Avery

Amerikan Bord

Neşriyat Dairesi

Posta Kutusu 142

istanbul

May 6, 1957

Dear Mr. Avery,

Thank you for your letter of Apr. 29th. It is very kind of you to offer to do this checking of the classification for us.

Ikbal Argon who is the coordinator of the classification thinks that we should send you the whole section on Religion, but I think it is really too much to ask you to check. My original idea was to ask you to check sections 230 and 260-280, dealing primarily with the Christian religion.

However I am enclosing the whole classification of Religion with the Turkish translation. If your staft have time we would be delighted if they could check the whole thing. We hope the translation is correct as it is. What we want to avoid is mistakes in terminology particularly in the care of the Christian religion. Will they please write changes on the Turkish copy.

We, unfortunately have no second copy of the Turkish text to give you, but we have no objection at all to your copying any parts of it that you wish. We hope that the whole classification will be in print by this fall.

Thank you so much for your kind cooperation. We hope it will not be too long a process for your staff and that we can have the translation back in a couple of weeks.

Sincerely yours,

Mrs. Emily Dean 


\section{Mektup 7: E. Dean'den Mr. Kerwin ve Mr. Adamson'a}

\section{MEMORANDUM}

DATE: May 14, 1957

TO

FROM : Emily Dean

: Mr. Kerwin

\author{
Mr. Adamson
}

SUBJECT : Printing of the Dewey Decimal classification.

The translation of this classification is completed, the checking by two Turks approved by the Ministry of Education is more than half completed and will be finished in another month or so. Ikbal Argon continues to oversee this and is retyping the corrected classification in final form for the printer. When the last of the checking is completed she will start making the index.

As the classification has been needed and will be needed for use in the Library school next fall, it is essential to get it in print as soon as possible. Following is a brief resume of what has been done.

May 15, 1952, USIS entered with a contract with the Ministry of Education to purchase paper to publish 1500 copies of this book, and gave 5,460 T.L. for this purpose, (copy of English translation of contract attached). A month or so ago Muhtar Bey was investigating the receipt of this money and found that the paper had been purchased and was in the ware house of the Ministry with other paper also purchased probably for other USIS translations. He got a receipt from the Ministry showing where this paper is.

Under the original plan the Ministry of Education was to print and publish the book in their printing plant. Adnan Ötüken, Director of the National Library, who is much concerned with this book, anxious to have it published, and who has been our contact with the Ministry of Education, is unfortunately leaving soon, probably this summer to become an education attache abroad.

He says that the Ministry of Education presses are overloaded with work and would probably not be able to publish the book for a year. Also the press 
in Ankara is not too good, and such a complicated thing as the Classification would have to be printed on the press in Istanbul. This would make the checking of proofs and the corrections much more difficult from Ankara. Also the Ministry would insist on having the whole manuscript in hand before starting printing, which would make for further delays, as the first half of the book is ready for the printing now.

Adnan Ötüken has always had the idea that the Classification should be printed by the excellent press of the Türk Tarih Kurumu in Ankara, which is a better press, mono-type, and has more variety of type faces than the Ministry of Education press in Istanbul (For the Classification a great variety of sizes and kinds of type are needed). Also they could print it much more quickly and would nod have to have the completed manuscript before beginning. And they have the great advantage of being in Ankara.

Although the Ministry of Education agreed to print this Classification if we furnished the paper, Adnan Bey says that they would not pay the Türk Tarih Kurumu to print it for them. As it is highly desireable to have the Kurum do it, it seems to me that there are two ways by which this could be managed.

1. Take back all the paper from the Ministry of Education and give part of it in excess of what is needed for the Classification to the Kurum in lieu of paying them for the cost of printing and binding. In this way USIS would not have to obligate other funds.

2. If the Kurum did nor wish to accept the paper then the USIS would pay them for printing costs out or funds for the translation program, and use the extra paper for other program translations.

Before approaching the Türk Tarih Kurumu about printing the Classification, we must know on what basis we can ask them to print it. I would like a chance to talk this all over with you as soon as possible, as it is important to start on the printing if we are going to have the book ready by fall.

I am sure you both realize how important this Classification is and what a great and lasting contribution it will be to library development in Turkey. 